\title{
Disseminated Cutaneous Leishmaniasis and Alcohol Misuse, Northeast Brazil, 2015-2018
}

\author{
Anastácio Q. Sousa, Pedro D.T. Sindeaux Filho, Diane I.M. Cavalcante, \\ Mércia S. Frutuoso, Francisco F. Pereira, José W.O. Lima, Laécio P.S. Santos, \\ José A.N. Queiroz, James H. Maguire, Richard D. Pearson, Margarida M.L. Pompeu
}

Disseminated cutaneous leishmaniasis (DCL) is an uncommon form of Leishmania braziliensis infection. It remains unknown why some people develop this clinical condition. We describe 14 DCL patients in Northeast Brazil during 2015-2018. These patients regularly drank large amounts of alcohol, possibly increasing their risk for DCL.

L eishmaniasis is a parasitic disease caused by infection with Leishmania parasites, which are transmitted by the bites of phlebotomine sand flies. Localized cutaneous leishmaniasis (LCL), disseminated cutaneous leishmaniasis (DCL), and mucosal leishmaniasis are clinical manifestations of L. braziliensis infection. DCL was initially described in the 1980s $(1,2)$; in 2002, Turetz et al. (2) defined DCL as $\geq 10 \mathrm{cu}-$ taneous lesions (papular, nodular, acneiform, crusted, or ulcerated) on $\geq 2$ anatomic regions of the body (i.e., the head, trunk, upper, and lower extremities). L. guyanensis, L. panamensis, and L. peruviana parasites also cause DCL in the New World, whereas L. tropica and L. major cause DCL in the Old World (3). DCL is distinct from anergic diffuse cutaneous leishmaniasis caused by L. amazonensis, L. mexicana, and L. aethiopica infections; anergic diffuse cutaneous leishmaniasis causes multiple nonulcerating, nonhealing lesions in immunocompromised persons (3).

In Ceará, a state in Northeast Brazil, only L. braziliensis has been isolated from persons who have LCL or DCL (4). We observed that many DCL patients in

\footnotetext{
Author affiliations: Hospital São José for Infectious Diseases, Fortaleza, Brazil (A.Q. Sousa); Federal University of Ceará, Fortaleza (A.Q. Sousa, P.D.T. Sindeaux Filho, D.I.M. Cavalcante, M.S. Frutuoso, F.F. Pereira, L.P.S. Santos, J.A.N. Queiroz, M.M.L. Pompeu); State University of Ceará, Fortaleza (J.W.O. Lima); Harvard University, Boston, Massachusetts, USA (J.H. Maguire); University of Virginia, Charlottesville, Virginia, USA (R.D. Pearson)
}

DOI: https://doi.org/10.3201/eid2709.203714 this region report heavy alcohol use. An excessive intake of alcohol can impair the immune response and increase susceptibility to viral and bacterial infections (5). Carvalho et al. (1) postulated that DCL patients might have a weaker cellular immune response to Leishmania spp. than LCL patients. We assessed the association of DCL with heavy alcohol consumption in a region to which L. braziliensis is endemic.

\section{The Study}

We conducted the case-control study in an outpatient clinic in the Baturité region, Ceará state, Northeast Brazil, during 2015-2018, when 358 LCL and DCL cases were diagnosed. We identified 18 DCL patients and 38 LCL patients matched by sex, age (within \pm 5 years), and time of diagnosis. All DCL cases fulfilled the criteria set by Turetz et al. (2). Patients with known causes of immunosuppression and pregnant or lactating women were excluded from the study. We collected data on the duration of skin lesions, number and type of lesions, mucosal involvement, underlying conditions (e.g., diabetes, hypertension, etc.) and diagnostic method (i.e., culture, smears, histopathology, or immunohistochemical [IHC] assay). Our histopathological diagnoses were based on inflammatory cell infiltrate patterns and the presence of granulomas and amastigotes. For IHC assays, we used the EnVision FLEX HRP Magenta, High pH (Dako Omnis) kit (Agilent Technologies, https://www.agilent.com) with murine hyperimmune serum from mice infected with Leishmania braziliensis. We defined parasite load as the number of intracellular and extracellular amastigotes in 15 high-powered fields $(\times 40)$ using IHC assays. This work was approved by the Human Ethics Committee of the Federal University of Ceará (Fortaleza, Brazil) (protocol no. 1.552.232 e CAAE 53919816.2.0000.5054).

Participants completed a standardized questionnaire (i.e., the Alcohol Use Disorder Identification Test) 
to estimate the amount of alcohol intake in grams per day (6). We considered $\geq 28 \mathrm{~g} / \mathrm{d}$ to be a high level of alcohol consumption (7). Most DCL patients were men 19-77 years of age with a duration of disease ranging from 5-36 weeks at diagnosis of leishmaniasis. Each patient had 13-720 lesions on their trunk, limbs, scalp, face, eyelids, conjunctivae, lips, ears, palms, soles of the feet, or genitalia (Figure). Most (56.3\%) patients had lesions in the nasal mucosa. Seventeen patients had $\geq 1$ ulcerated lesion; in patient 5 , all lesions were ulcerated (Table 1).

DCL and LCL patients were well-matched by sex and age (Table 2). DCL patients had longer durations of disease before diagnosis than LCL patients $(\mathrm{p}<0.01)$. All LCL lesions were ulcerated and found predominantly in exposed skin areas: lower limbs (50\%), upper limbs $(25 \%)$, head $(10 \%)$, and trunk (5\%). In total, 36 (92\%) LCL patients had 1-2 lesions; the other $3(8 \%)$ patients had 3, 5, and 6 lesions. We observed nasal mucosa involvement in only 1 LCL patient.

In total, 14 (78\%) DCL patients drank alcohol in the form of cachaça, a popular beverage made by distilling fermented sugar cane juice (8). Cachaça has an alcohol content of $40 \%$, similar to that of other distilled spirits such as whiskey, tequila, and vodka. One liter of cachaça or whiskey contains $400 \mathrm{~g}$ of pure alcohol. For the 14 patients who drank cachaça, alcohol intake ranged from $45-800 \mathrm{~g} / \mathrm{d}$. Twelve (67\%) DCL patients drank $\geq 350 \mathrm{~mL}$ of cachaça (140 g of alcohol) daily. The other 4 (22\%) DCL patients did not drink alcohol, including 3 patients who had diabetes. LCL patients had a significantly lower alcohol intake than DCL patients $(\mathrm{p}<0.01)$. In total, $25(64 \%) \mathrm{LCL}$ patients did not drink alcohol. Fourteen (36\%) LCL patients reported alcohol consumption, including 4 who had alcohol intakes $\geq 28 \mathrm{~g} / \mathrm{d}, 3$ who had intakes of $28-50 \mathrm{~g} / \mathrm{d}$, and 1 who had an intake of $400 \mathrm{~g} / \mathrm{d}$. In addition, 3 LCL patients had diabetes. We found an association between alcohol intake and parasite load (Spearman $\rho=0.482 ; \mathrm{p}=0.03$ ).

\section{Conclusions}

The clinical manifestations of DCL in these patients did not differ substantially from those reported previously $(2,9)$. However, we observed 1 patient who had only ulcerated lesions and another with crustedhorny lesions, both uncommon forms of this rare disease (Figure). The duration of skin lesions before diagnosis was longer in persons with DCL than LCL, similar to the observations of Turetz et al. (2). Most DCL lesions were identified by histopathological assays. Our results suggest that DCL is associated with alcohol misuse.

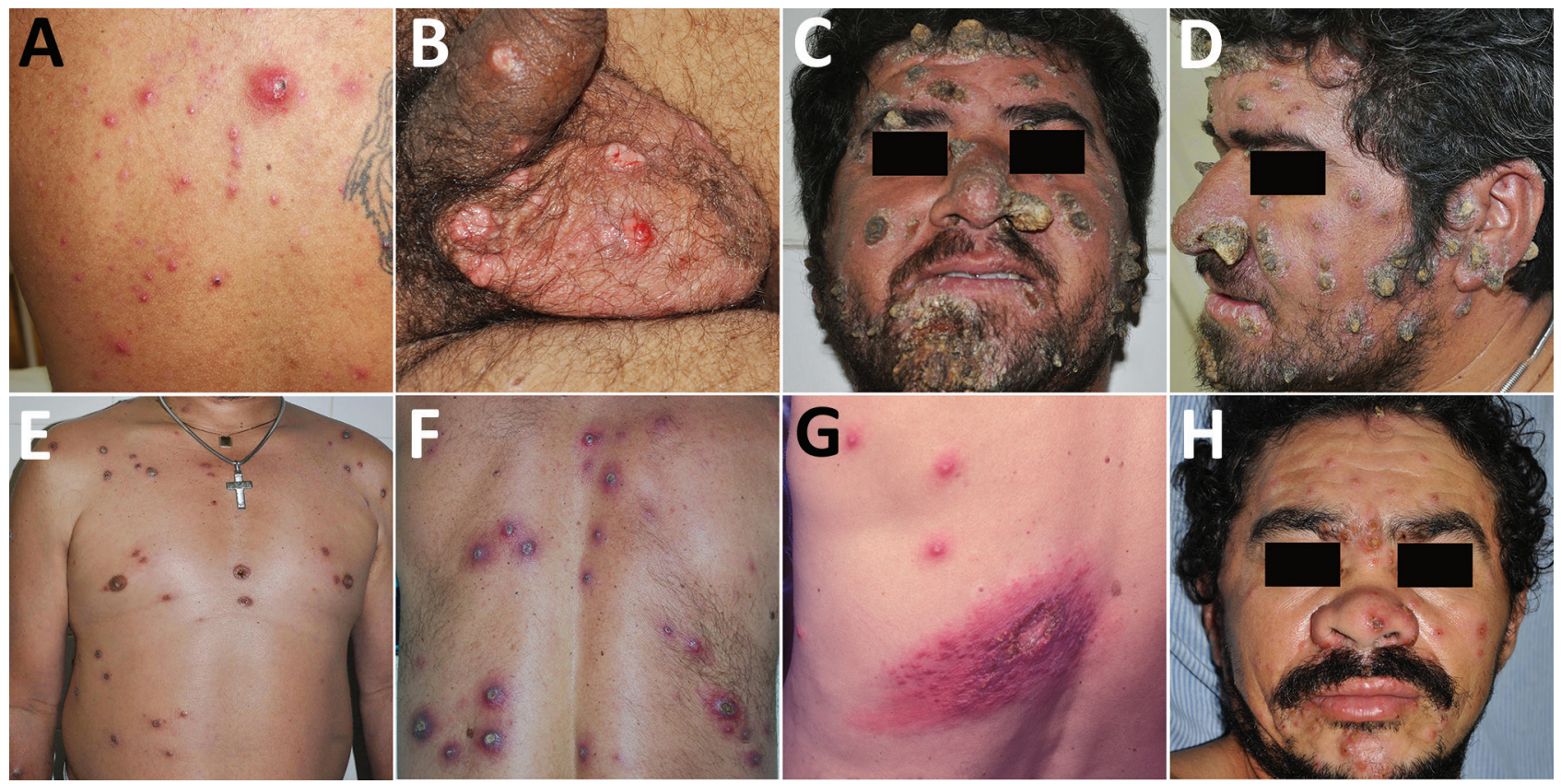

Figure. Lesions of patients with disseminated cutaneous leishmaniasis, Baturité region, Ceará State, Northeast Brazil, $2015-2018$. Patient numbers match those given in Table 1. A) Ulcerated, acneiform, and papular lesions on the back of patient 1. B) Ulcerated lesions on the genitalia of patient 2. C-D) Crusted and crusted-horny lesions on the face of patient 3. E) Papular, crusted, and ulcerated lesions on the trunk of patient 3. F) Crusted, ulcerated, and papular lesions on the back of patient 6. G) Ulcer surrounded by zosteriform and papular lesions on the back of patient 11. H) Papular, crusted, and ulcerated lesions on the face as well as an ulcerated and crusted-horny lesion on the superior right eyelid of patient 12 . 
Table 1. Clinical, diagnostic and alcohol intake data of 18 patients with disseminated cutaneous leishmaniasis, Baturité region, Ceará State, Northeast Brazil, 2015-2018*

\begin{tabular}{|c|c|c|c|c|c|c|c|}
\hline Patient ID & $\begin{array}{c}\text { Alcohol } \\
\text { intake, g/d }\end{array}$ & Age, $y /$ sex & $\begin{array}{c}\text { Duration of } \\
\text { lesions, } \\
\text { wkst }\end{array}$ & No. lesions & Lesion type(s) & $\begin{array}{c}\text { Mucosal } \\
\text { lesions }\end{array}$ & $\begin{array}{c}\text { Diagnostic } \\
\text { method }\end{array}$ \\
\hline 1 & 800 & $25 / \mathrm{M}$ & NA & 79 & $\mathrm{U}, \mathrm{Ac}, \mathrm{P}$ & No & $\mathrm{H}$ \\
\hline 2 & 600 & $41 / \mathrm{M}$ & 16 & 184 & $\mathrm{Cr}, \mathrm{U}$ & Yes & $\mathrm{H}$ \\
\hline 3 & 400 & $36 / \mathrm{M}$ & 16 & 167 & $\begin{array}{l}\mathrm{U}, \mathrm{Cr} \text {, crusted- } \\
\text { horny, } \mathrm{P}\end{array}$ & Yes & $\mathrm{C}, \mathrm{H}, \mathrm{I}$ \\
\hline 4 & 400 & $60 / \mathrm{M}$ & 5 & 13 & $\mathrm{U}, \mathrm{P}$ & No & $\mathrm{H}$ \\
\hline 5 & 400 & $41 / \mathrm{M}$ & NA & 24 & U & NA & $\mathrm{H}$ \\
\hline 6 & 400 & 49/M & 16 & 171 & $U, N, A c, P$ & No & $\mathrm{H}, \mathrm{I}$ \\
\hline 7 & 400 & $44 / \mathrm{M}$ & 32 & 720 & $\mathrm{U}, \mathrm{P}, \mathrm{Ac}$ & Yes & $\mathrm{H}, \mathrm{I}$ \\
\hline 8 & 300 & $51 / \mathrm{M}$ & 36 & 110 & $\mathrm{U}, \mathrm{N}$ & NA & $\mathrm{H}$ \\
\hline 9 & 240 & $73 / \mathrm{M}$ & 24 & 20 & $\mathrm{U}, \mathrm{Cr}, \mathrm{N}$ & No & $\mathrm{H}$ \\
\hline 10 & 230 & $47 / \mathrm{M}$ & 24 & 18 & $\mathrm{U}, \mathrm{Cr}, \mathrm{P}$ & No & $\mathrm{C}, \mathrm{H}$ \\
\hline 11 & 170 & $39 / \mathrm{M}$ & 18 & 37 & $\begin{array}{c}\mathrm{P}, \mathrm{U} \\
\text { zosteriform }\end{array}$ & Yes & $\mathrm{H}$ \\
\hline 12 & 140 & $38 / \mathrm{M}$ & 6 & 71 & $\begin{array}{c}\mathrm{P}, \mathrm{Cr}, \mathrm{U}, \\
\text { crusted-horny }\end{array}$ & Yes & $\mathrm{C}, \mathrm{H}, \mathrm{I}$ \\
\hline 13 & 60 & 19/M & 12 & 14 & $\mathrm{U}, \mathrm{Cr}, \mathrm{P}$ & No & $\mathrm{H}, \mathrm{C}$ \\
\hline 14 & 45 & $32 / \mathrm{M}$ & 32 & 421 & $\mathrm{U}, \mathrm{P}, \mathrm{Cr}, \mathrm{N}$ & Yes & $\mathrm{C}, \mathrm{H}$ \\
\hline 15 & 0 & $77 / \mathrm{M}$ & 32 & 22 & $\mathrm{U}, \mathrm{N}, \mathrm{Ac}$ & Yes & $\mathrm{H}$ \\
\hline 16 & 0 & $34 / F$ & 8 & 41 & $\mathrm{U}, \mathrm{N}$ & Yes & $\mathrm{H}$ \\
\hline 17 & 0 & $71 / F$ & 8 & 19 & U, P & No & $\mathrm{H}$ \\
\hline 18 & 0 & $42 / \mathrm{M}$ & NA & 60 & $\mathrm{U}, \mathrm{N}, \mathrm{Cr}$ & Yes & $\mathrm{C}, \mathrm{H}$ \\
\hline
\end{tabular}

Alcohol causes dysregulation of the innate and adaptive immune responses (10). Persons who misuse alcohol have decreased tissue recruitment of neutrophils during bacterial infections and substantial defects in neutrophil function. In addition, these persons have dendritic cells that are fewer in number and have impaired differentiation and function (11), possibly causing an imbalance toward a Th2 profile $(12,13)$. Persons who misuse alcohol produce macrophages with decreased phagocytic and microbicidal activity as well as reduced adherence to other cells in the lesion, which increases their migration to the circulatory system $(5,13)$. These immune anomalies could explain the correlation between alcohol misuse and parasite load in DCL patients. Vitamin and micronutrient deficiencies are also common in persons who misuse alcohol (14) and might also contribute to risk for DCL.

Other risk factors might also contribute to the pathogenesis of DCL. For example, younger age and male sex are associated with DCL (2); we controlled for these variables in our analysis. Different strains of L. braziliensis might also account for the differential manifestations of LCL and DCL. Cardoso et al. (15) showed that neutrophils from healthy persons had decreased microbicidal activity when infected

\begin{tabular}{|c|c|c|c|c|}
\hline Variable & $\begin{array}{l}\text { Localized cutaneous } \\
\text { leishmaniasis }\end{array}$ & $\begin{array}{c}\text { Disseminated cutaneous } \\
\text { leishmaniasis }\end{array}$ & Odds ratio† & $p$ value \\
\hline Total & $38(100.0)$ & $18(100.0)$ & & \\
\hline \multicolumn{5}{|l|}{ Sex } \\
\hline M & $35(92.1)$ & $16(88.9)$ & 1.00 & 0.7 \\
\hline $\mathrm{F}$ & $3(7.9)$ & $2(11.1)$ & 1.46 & \\
\hline Age, y $\ddagger$ & $41(19-89)$ & $42(19-77)$ & 1.01 & 0.64 \\
\hline Diabetes & $3(7.9)$ & $3(16.7)$ & 2.13 & 0.39 \\
\hline Disease duration, wks $\ddagger$ & $8(3-26)$ & $16(5-36)$ & 1.17 & $<0.01$ \\
\hline Mucosal lesion & $1(2.6)$ & $9(50.0)$ & 43.7 & $<0.01$ \\
\hline Parasite load $\neq \S$ & $3(1-340)$ & $5(1-556)$ & 1.002 & 0.53 \\
\hline Agricultural occupation & $22(57.9)$ & $12(66.7)$ & 1.45 & 0.53 \\
\hline Daily alcohol intake, g/d $\ddagger$ & $0(0-400)$ & $325(0-800)$ & 1.01 & $<0.01$ \\
\hline Days with alcohol intake $>28 \mathrm{~g}$ & $4(10.5)$ & $14(77.8)$ & 23 & $<0.01$ \\
\hline
\end{tabular}

*Values are no. (\%), except as indicated. DCL, disseminated cutaneous leishmaniasis; LCL, localized cutaneous leishmaniasis.

†Estimated by simple logistic regression.

$\ddagger$ Values are median (range). Load measured as the number of intracellular and extracellular amastigotes in 15 high-powered fields $(\times 40)$ using immunohistochemical assays.

§Of $6 \mathrm{LCL}$ patients and $7 \mathrm{DCL}$ patients. 
with parasites from DCL patients compared with LCL patients.

In summary, we found an association between DCL and heavy alcohol use. Excessive alcohol intake impairs the human immune system. We postulate that alcohol misuse is a risk factor for DCL in persons infected with L. braziliensis. Additional studies are needed to determine whether this association is causal, and if so, to elucidate the mechanism(s) of immune dysregulation responsible for development of DCL in persons infected with L. braziliensis. Health officials should consider campaigns focused on preventing sand fly bites in persons who misuse alcohol.

\section{About the Author}

Dr. Sousa is head of the department of Clinical Medicine at the Federal University of Ceará in Fortaleza, Brazil. His primary research interests are leishmaniasis and other emerging infectious diseases in Northeast Brazil.

\section{References}

1. Carvalho EM, Barral A, Costa JM, Bittencourt A, Marsden P. Clinical and immunopathological aspects of disseminated cutaneous leishmaniasis. Acta Trop. 1994;56:315-25. https://doi.org/10.1016/0001-706X(94)90103-1

2. Turetz ML, Machado PR, Ko AI, Alves F, Bittencourt A, Almeida RP, et al. Disseminated leishmaniasis: a new and emerging form of leishmaniasis observed in northeastern Brazil. J Infect Dis. 2002;186:1829-34. https:// doi.org/10.1086/345772

3. Hashiguchi Y, Gomez EL, Kato H, Martini LR, Velez LN, Uezato H. Diffuse and disseminated cutaneous leishmaniasis: clinical cases experienced in Ecuador and a brief review. Trop Med Health. 2016;44:2. https:/ / doi.org/10.1186/ s41182-016-0002-0

4. Sousa AQ, Parise ME, Pompeu MML, Coelho Filho JM, Vasconcelos IAB, Lima JWO, et al. Bubonic leishmaniasis: a common manifestation of Leishmania (Viannia) braziliensis infection in Ceara, Brazil. Am J Trop Med Hyg. 1995;53: 380-5. https://doi.org/10.4269/ajtmh.1995.53.380
5. Szabo G, Saha B. Alcohol's effect on host defense. Alcohol Res. 2015;37:159-70.

6. World Health Organization. AUDIT: The Alcohol Use Disorders Identification Test: guidelines for use in primary health care. 2001 [cited 2021 Mar 25]. https:/ /apps.who.int/ iris/handle/10665/67205

7. US Centers for Diseases Control and Prevention. Alcohol use and your health. 2021. [cited 2021 Mar 25]. https:/ / www. cdc.gov/alcohol/fact-sheets/alcohol-use.htm

8. Alcarde AR, Souza PA, Belluco AES. Chemical profile of sugarcane spirits produced by double distillation methodologies in rectifying still. Food Sci Technol (Campinas). 2011;31:355-60. https:/ / doi.org/10.1590/ S0101-20612011000200012

9. Machado PR, Rosa MEA, Costa D, Mignac M, Silva JS, Schriefer A, et al. Reappraisal of the immunopathogenesis of disseminated leishmaniasis: in situ and systemic immune response. Trans R Soc Trop Med Hyg. 2011;105:438-44. https:// doi.org/10.1016/j.trstmh.2011.05.002

10. Pasala S, Barr T, Messaoudi I. Impact of alcohol abuse on the adaptive immune system. Alcohol Res. 2015;37:185-97.

11. Parlet CP, Waldschmidt TJ, Schlueter AJ. Chronic ethanol feeding induces subset loss and hyporesponsiveness in skin T cells. Alcohol Clin Exp Res. 2014;38:1356-64. https:/ / doi.org/10.1111/acer.12358

12. Franchi S, Sacerdote P, Moretti S, Gerra G, Leccese V, Tallone MV, et al. The effects of alcoholism pharmacotherapy on immune responses in alcohol-dependent patients. Int J Immunopathol Pharmacol. 2010;23:847-55. https:/ / doi.org/10.1177/039463201002300320

13. Molina PE, Happel KI, Zhang P, Kolls JK, Nelson S. Focus on: alcohol and the immune system. Alcohol Res Health. 2010;33:97-108.

14. Fuchs J. Alcoholism, malnutrition, vitamin deficiencies, and the skin. Clin Dermatol. 1999;17:457-61. https:/ / doi.org/ 10.1016/S0738-081X(99)00032-2

15. Cardoso T, Bezerra C, Medina LS, Ramasawmy R, Scheriefer A, Bacellar O, et al. Leishmania braziliensis isolated from disseminated leishmaniasis patients downmodulate neutrophil function. Parasite Immunol. 2019;41:e12620. https:// doi.org/10.1111/pim.12620

Address for correspondence: Anastácio Q. Sousa, Department of Clinical Medicine, School of Medicine, Federal University of Ceará. Rua Prof. Costa Mendes, 1608-4o. andar-Rodolfo Teófilo, CEP 60.430-140, Fortaleza, Ceará, Brazil; email: aqsousa@gmail.com 